\title{
Locomotor rhythm and pattern generating networks of the human lumbar spinal cord: an electrophysiological and computer modeling study
}

\author{
Simon M Danner ${ }^{1,2^{*}}$, Frank Rattay ${ }^{1}$, Ursula S Hofstoetter ${ }^{2}$, Milan R Dimitrijevic ${ }^{3}$, Karen Minassian ${ }^{2}$ \\ From Twenty Second Annual Computational Neuroscience Meeting: CNS*2013 \\ Paris, France. 13-18 July 2013
}

The concept of the neural control of human locomotion has undergone changes in the past decades. In spite of the encephalization and the erect, bipedal mode of walking, independent observations imply that unperturbed locomotor patterns can be generated by similar spinal neural circuits as in other vertebrates [1,2]. However, little is known about the organization of these rhythm and pattern generating networks in humans. It has been shown that the human lumbar spinal cord isolated from supraspinal control due to traumatic spinal cord injury (SCI) can generate rhythmic, locomotor-like activity in response to sustained epidural spinal cord stimulation of certain frequencies [1]. In the supine position, in which the subjects were tested, afferent feedback is minimized. The rhythmic activities consist of a series of stimulus time-related rhythmically modulated posterior-root muscle (PRM) reflexes, each initiated in posterior root afferents and electromyographically recorded as compound muscle action potentials (CMAPs) [3]. The relation between individual stimuli and responses, as well as their characteristics, allow for the identification of mechanisms beyond the information gained from the overall electromyographic (EMG) patterns.

Here, EMG activities of quadriceps, hamstrings, tibialis anterior and triceps surae, bilaterally in response to epidural stimulation at $20 \mathrm{~Hz}-40 \mathrm{~Hz}$ were analyzed in 10 individuals with motor complete posttraumatic SCI. Forty segments (duration: $10 \mathrm{~s}$ ) of rhythmical activities found in all four-muscle groups of one lower limb at the same time were identified in 7 subjects. Phases of bursting and suppressed activities were identified. Latencies of PRM reflexes were calculated. Furthermore, a computational network model of neurons with Hodgkin-Huxley-like membrane dynamics was developed to test whether hypothesized rhythm and pattern generating networks would reproduce the recorded data. A core rhythmgenerating network model [4] was extended by adding conduction delays, presynaptic inhibition and disinhibition of parallel central pathways.

In all 10-s segments, rhythmical activities of all muscle groups had the same cycle frequency. In-between muscles, rhythmic activity occurred either synchronous or alternating, within phases resembling flexion or extension. No other phase-relations were observed. PRM reflexes constituting bursts during the extension phases had monosynaptic latencies. These responses were suppressed during flexion and were replaced by delayed, oligosynaptic PRM reflexes in quadriceps, tibialis anterior and triceps surae. Computer simulation confirmed that a network model with a half-center organization, phasic modulation of the monosynaptic reflex gain, presynaptic control of primary afferents together with the selection of alternative interneuronal pathways (within the flexor half-center) reliably reproduce the electrophysiological findings.

The electrophysiological data as well as the computer simulations give insight into the organization of the human spinal rhythm and pattern generating networks and reveal common control characteristics with the central pattern generators for locomotion described in animal experimental work.

\footnotetext{
* Correspondence: simon.danner@gmail.com

${ }^{1}$ Institute for Analysis and Scientific Computing, Vienna University of

Technology, Vienna, Austria

Full list of author information is available at the end of the article
}

(c) 2013 Danner et al; licensee BioMed Central Ltd. This is an Open Access article distributed under the terms of the Creative Commons Attribution License (http://creativecommons.org/licenses/by/2.0), which permits unrestricted use, distribution, and reproduction in any medium, provided the original work is properly cited. 


\section{Acknowledgements}

Vienna Science and Technology Fund (WWTF), LS11-057; Wings for Life Foundation (WfL), WFL-AT-007/11.

\section{Author details}

'Institute for Analysis and Scientific Computing, Vienna University of Technology, Vienna, Austria. ${ }^{2}$ Center for Medical Physics and Biomedical Engineering, Medical University of Vienna, Vienna, Austria. ${ }^{3}$ Baylor College of Medicine, Houston, TX, USA.

Published: 8 July 2013

\section{References}

1. Dimitrijevic MR, Gerasimenko Y, Pinter MM: Evidence for a spinal central pattern generator in humans. Ann N Y Acad Sci 1998, 860:360-376

2. Grillner S: Human locomotor circuits conform. Science 2011, 334:912-913.

3. Minassian K, Jilge B, Rattay F, Pinter MM, Binder H, Gerstenbrand F, Dimitrijevic MR: Stepping-like movements in humans with complete spinal cord injury induced by epidural stimulation of the lumbar cord: electromyographic study of compound muscle action potentials. Spinal Cord 2004, 42:401-416.

4. Rybak IA, Shevtsova NA, Lafreniere-Roula M, McCrea DA: Modelling spinal circuitry involved in locomotor pattern generation: insights from deletions during fictive locomotion. J Physiol 2006, 577:617-639.

doi:10.1186/1471-2202-14-S1-P274

Cite this article as: Danner et al:: Locomotor rhythm and pattern generating networks of the human lumbar spinal cord: an electrophysiological and computer modeling study. BMC Neuroscience 2013 14(Suppl 1):P274.

\section{Submit your next manuscript to BioMed Central} and take full advantage of:

- Convenient online submission

- Thorough peer review

- No space constraints or color figure charges

- Immediate publication on acceptance

- Inclusion in PubMed, CAS, Scopus and Google Scholar

- Research which is freely available for redistribution

Submit your manuscript at www.biomedcentral.com/submit 